\title{
Obstructive sleep apnea, verbal memory, and executive function in a community-based high-risk population identified by the Berlin Questionnaire Akershus Sleep Apnea Project
}

\author{
Harald Hrubos-Strøm • Inger H. Nordhus • \\ Gunnar Einvik • Anna Randby • Torbjørn Omland • \\ Kjetil Sundet • Torbjørn Moum • Toril Dammen
}

Received: 1 December 2010 /Revised: 12 January 2011 /Accepted: 31 January 2011 / Published online: 25 February 2011

(C) The Author(s) 2011. This article is published with open access at Springerlink.com

\begin{abstract}
Purpose Cognitive functions in community-dwelling adults at high risk of obstructive sleep apnea have not been described and nor are associations between cognitive functions and obstructive sleep apnea severity fully understood. The study aimed to describe verbal memory and executive function in community-dwelling adults identified by the Berlin Questionnaire and to investigate associations between these cognitive domains and different obstructive sleep apnea severity indicators.
\end{abstract}

The Akershus Sleep Apnea Project is supported by the South-Eastern Norway Regional Health Authority, grant number 2004219 and the University of Oslo, Norway.

Electronic supplementary material The online version of this article (doi:10.1007/s11325-011-0493-1) contains supplementary material, which is available to authorized users.

\section{H. Hrubos-Strøm $(\square)$}

Department of Clinical Science, Research Centre,

Akershus University Hospital,

1478 Lørenskog, Norway

e-mail: Harald.hrubos-strom@medisin.uio.no

H. Hrubos-Strøm • G. Einvik • T. Moum • T. Dammen Department of Behavioural Sciences in Medicine, Institute of Basic Medical Sciences, University of Oslo, Oslo, Norway

H. Hrubos-Strøm • G. Einvik • A. Randby • T. Omland Institute for clinical medicine, University of Oslo,

Oslo, Norway

I. H. Nordhus

Department of Clinical Psychology, University of Bergen,

5015 Bergen, Norway
Methods Among 29,258 age- and gender-stratified persons 30-65 years who received the Berlin Questionnaire by mail, 16,302 (55.7\%) responded. From 654 randomly drawn respondents with BQ high risk who were approached for study participation, 290 participants (55.9\% males, mean age 48.2 years) were included. Verbal memory was assessed by Rey Auditory Verbal Learning Test and executive function by Stroop test. Obstructive sleep apnea severity indicators were assessed by polysomnography.

\section{H. Nordhus}

National Competence Centre of Sleep Disorders,

Haukeland University Hospital,

Bergen, Norway

G. Einvik · A. Randby

Division of Medicine,

Akershus University Hospital,

Oslo, Norway

K. Sundet

Department of Psychology, University of Oslo,

Oslo, Norway

T. Dammen

Department of Psychiatry,

Oslo University Hospital Ullevål,

Oslo, Norway 
Results Mean (standard deviation) verbal learning score was 42.0 (8.9), mean interference time was 31.1 (12.7), median (25th percentile, 75 th percentile) apnea-hypopnea index was 7.7 (2.4-22.2), and mean average oxygen saturation was 94.3 (2.0). Verbal learning score was independently associated with average oxygen saturation $(\beta=0.721, p=0.025)$ in multivariate linear regression models adjusted for putative confounders. Interference time was only related to OSA severity indicators in bivariate analyses.

Conclusions Verbal memory and executive function impairments were mild in community-dwelling adults at high risk of obstructive sleep apnea. Average oxygen saturation was the indicator of obstructive sleep apnea severity most strongly associated with cognitive function.

Keywords Neurobehavioural manifestations .

Polysomnography · Epidemiology · Sleep apnea

syndromes $\cdot$ Sleep disordered breathing

\section{Introduction}

The association between moderate to severe obstructive sleep apnea (OSA) and impaired neurocognitive function is wellestablished [1-6]. It is unclear whether this association is related to intermittent oxygen desaturations or the repeated arousals of OSA [1-6]. Neurocognitive function consists of basal processes (i.e., attention, motor speed, and vigilance) and more differentiated cognitive functions, of which impairments in verbal memory $[7,8]$ and executive functioning [9-11] have been found to be most strongly related to OSA. However, findings of cognitive impairments in patients with moderate to severe OSA have not been consistently reproduced in community-based studies.

We identified seven community-based studies [12-18] and two studies of mild OSA in volunteers $[19,20]$ that assessed cognitive function with rater-administered instruments in addition to objective sleep measures. Four studies reported associations between OSA and at least one cognitive domain $[13,14,19,20]$. Affected cognitive domains were verbal memory (Wechsler Memory Scale [13], declarative memory factor [20]), and working memory (composite factor [20]), spatial orientation (Clock Test [13]), executive function (Wechsler Adult Intelligence Scale-Revised Digits Backward Subtest [19]), and cerebral efficiency (composite factor [14]).

Five of the identified studies reported analyses by variables assessing oxygen saturation (4\% oxygen desaturation index, lowest oxygen saturation, or percentage time below $90 \%$ oxygen saturation $[13,16-18,20])$. In all these studies, the associations with oxygen saturation were at least as strong as the associations reported between cognitive functions and apnea-hypopnea indices (AHIs). The average oxygen saturation during sleep has recently been associated with cerebrovascular regulation in community-dwelling adults [21]. None of the identified community-based studies reported analyses by the arousal index.

In addition to the question of which mechanisms of OSA are associated with cognitive impairment, the relative importance of sociodemography and other potential health-related factors, such as alcohol abuse, sleepiness, use of hypnosedatives, smoking, and asthma [15-17, 19, 20], are not fully understood. The present study is unique in terms of including a large, community-based sample of participants identified by the Berlin Questionnaire (BQ) [22] as being at risk of OSA. The BQ is a widely used screening tool for OSA that has been used as a proxy for OSA diagnosis in nationwide US telephone surveys [23, 24] and validated in the Norwegian general population [25]. We are not aware of any study of cognitive function in a strictly defined probability sample of OSA. We aimed to (1) characterize cognitive function among community-based, BQ high-risk participants; and (2) investigate associations between verbal memory, executive function, and OSA severity as assessed by the AHI, indicators of oxygen saturation, and the arousal index before and after adjustment for putative confounders such as age, gender, comorbid conditions (alcohol abuse, asthma), use of hypnosedatives, sleepiness, smoking, and educational level. We hypothesized that verbal memory and executive function would be more closely related to variables assessing oxygen saturation than the AHI or the arousal index.

\section{Materials and methods}

\section{Participants}

The study population consisted of 29,258 persons (aged $30-65$ years, $50 \%$ female) of whom $16,302(55.7 \%)$ completed the BQ [22] (Fig. 1). Of them, 3,960 (24.3\%) were classified at risk of OSA according to the BQ scoring algorithm [26], which defines three risk categories: (I) snoring, (II) daytime somnolence, and (III) obesity or selfreported hypertension (Table 1). Obesity was defined as a body mass index (BMI) $>30 \mathrm{~kg} / \mathrm{m}^{2}$ calculated from selfreported weight and height. High risk on the BQ was defined as any combination of two or three of these categories [26].

From the 3,960 BQ high-risk persons classified at risk for OSA, 1,085 (27.4\%) were randomly drawn and 852 of them were asked to participate in the Akershus Sleep Apnea Project (ASAP) for clinical investigations. Persons with established cardiovascular disease, diabetes, or previous otitis media surgery were oversampled. The reason that not all 1,085 were asked to participate was that, after the 


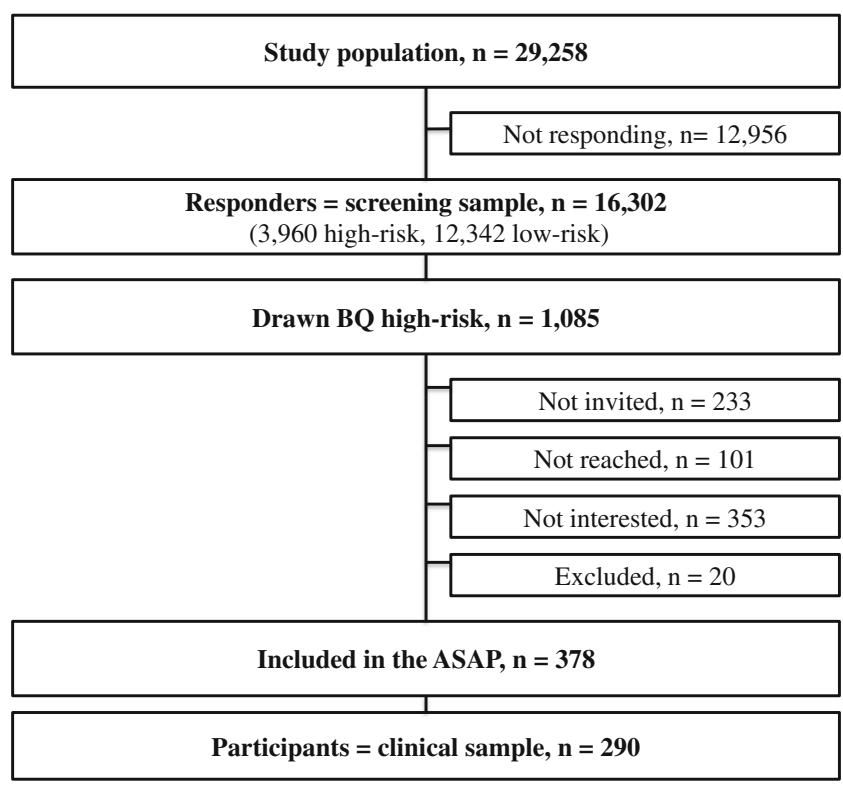

Fig. 1 Diagram to show the flow of persons from the study population to the final inclusion of participants

predefined strata were saturated, the invitation process was stopped. Altogether, 101 persons were not reached by telephone after three attempts; 353 declined participation; 233 not approached, and 20 were excluded according to the following exclusion criteria: use of continuous positive airway pressure $(n=10)$, pregnancy $(n=4)$, inadequate Norwegian language skills $(n=4)$, and severe physical impairment as defined by inability to walk the stairs of our sleep laboratory $(n=2)$. This recruitment procedure resulted in 378 participants which was $44.3 \%$ from 852 . The present sample comprises consecutive, BQ high-risk persons included in the ASAP between 1 June 2006 and 31 March 2007. During this time, 654 persons had been approached and 290 participants (44.3\%) were included.

Measures

\section{Cognitive function}

The Rey Auditory Verbal Listening Test (RAVLT) [27] was used to assess verbal memory. The RAVLT score, which is the sum of words retrieved from hearing 15 common words five times (range, 0-75), was calculated.

A shortened version of the Comali/Kaplan Stroop test [28] was used to assess response inhibition, which is regarded as a measure of executive function. The score computed was Stroop interference time, the time used on a task requiring response inhibition minus the average time used to name 48 colored patches and to read 48 color
Table 1 Description of the screening sample and the clinical sample
$A H I$ apnea-hypopnea index, $S D$ standard deviation

${ }^{\text {a }}$ Gram/deciliter

${ }^{\mathrm{b}}$ Microgram/liter

\begin{tabular}{|c|c|c|c|}
\hline & $\begin{array}{l}\text { Screening } \\
\text { sample } \\
n=3,960\end{array}$ & $\begin{array}{l}\text { Participants } \\
n=290\end{array}$ & $\begin{array}{l}p \\
\text { Value }\end{array}$ \\
\hline Age in years, mean $(\mathrm{SD})$ & $48.8(10.3)$ & $48.2(11.2)$ & 0.357 \\
\hline Male gender, $n(\%)$ & $2,198(55.5)$ & $162(55.9)$ & 0.899 \\
\hline Higher education, $n(\%)$ & & $80(28.1)$ & \\
\hline Body mass index, mean (SD) & $29.1(5.2)$ & $29.0(4.9)$ & 0.951 \\
\hline Smoking, $n(\%)$ & & $89(31.0)$ & \\
\hline Alcohol abuse, $n(\%)$ & & $5(1.7)$ & \\
\hline \multicolumn{4}{|l|}{ Berlin Questionnaire } \\
\hline Snoring category, $n(\%)$ & $3,654(92.3)$ & $264(91.0)$ & 0.412 \\
\hline Daytime somnolence category, $n(\%)$ & $2,498(63.1)$ & $205(70.7)$ & 0.005 \\
\hline Hypertension/obesity category, $n(\%)$ & $2,624(66.3)$ & $193(66.6)$ & 0.914 \\
\hline \multicolumn{4}{|l|}{ Sleepiness and comorbidities } \\
\hline Epworth Sleepiness Scale, mean (SD) & $8.8(4.5)$ & $9.5(4.2)$ & $<0.001$ \\
\hline Excessive daytime sleepiness, $n(\%)$ & $1,336(33.7)$ & $117(40.9)$ & $<0.001$ \\
\hline Self-reported asthma, $n(\%)$ & $597(16.5)$ & $50.0(18.8)$ & 0.289 \\
\hline \multicolumn{4}{|l|}{ Polysomnography indices } \\
\hline AHI, median (25th and 75th percentiles) & & $7.7(2.4,22.2)$ & \\
\hline Arousal index, mean (SD) & & $19.9(15.9)$ & \\
\hline $\begin{array}{l}\text { Nadir oxygen saturation, median (25th and } 75 \text { th } \\
\text { percentiles) }\end{array}$ & & $86.0(82.0,89.0)$ & \\
\hline Average oxygen saturation, mean (SD) & & $94.3(2.0)$ & \\
\hline \multicolumn{4}{|l|}{ Relevant standard blood tests } \\
\hline Blood hemoglobin ${ }^{\mathrm{a}}$, mean (SD) & & $15.1(1.2)$ & \\
\hline Serum ferritin ${ }^{\mathrm{b}}$, mean (SD) & & $121.5(96.0)$ & \\
\hline
\end{tabular}


names. Thus, a low score (seconds) indicates better executive function.

All assessments were made by the first author (HHS) before sleep registering.

\section{Sleep recordings}

Participants underwent in-hospital polysomnography, including two-channel electroencephalography (C4/A1 and C3/A2), two-channel electrooculography, one-channel submental electromyography, leg electromyography (tibialis), measurement of oxygen saturation by finger plethysmography (Nonin, Plymouth, MN, USA), assessment of breathing movements (Respitrace; Ambulatory Monitoring, Ardsley, NY, USA), nasal and oral air flow assessment (Protech, Woodinville, WA, USA), and body position monitoring. All electrophysiological signals were preamplified, stored and subsequently scored at 30 -s epochs using the Somnologica 3.2 software package (Flaga-Medcare, Buffalo, NY, USA) in accordance with the Rechtshaffen and Kales scoring manual [29] by two US board-certified polysomnography technicians who were blinded to the result of the BQ. Apneas were scored when airflow dropped below $10 \%$ of the reference amplitude for more than $10 \mathrm{~s}$. Hypopneas were scored when airflow dropped below $70 \%$ for more than $10 \mathrm{~s}$ with a subsequent oxygen desaturation of $4 \%$. Arousals were documented and classified according to standard criteria [30]. The AHI and arousal indices were calculated as the sum of apneas plus hypopneas and the sum of arousals per hours of sleep, respectively. The following variables of oxygen saturation were registered: the $4 \%$ oxygen desaturation index ( $4 \%$ ODI) [13], percent time $<90 \%$ saturation [16, 20], nadir oxygen saturation [20], and average oxygen saturation during sleep [21].

\section{Demographic and clinical characteristics}

Demographic data, BQ categories, sleepiness, and medical comorbidities were reported in the screening questionnaire 3-11 months prior to the overnight stay (Table 1). Educational level and smoking were reported during the overnight stay. Higher education was defined as having any college or university degree. A dichotomous variable of current smoking was computed, based on reported daily smoking. Missing information was replaced when possible by answers to other items assessing smoking. Diagnoses of alcohol abuse and/or dependency were determined by the structured clinical interview for Diagnostic and Statistical Manual for Mental Disorders [31] administered by the first author after measurement of cognitive function. The presence of asthma was assessed by self-report (yes/no) in the screening questionnaire. Sleepiness was assessed by a Norwegian translation of the Epworth Sleepiness Scale
(ESS) $[32,33]$. Excessive daytime sleepiness (EDS) was defined as a score $>10$ on the ESS. Blood hemoglobin and serum ferritin were analyzed from blood samples obtained in the morning after sleep registration.

\section{Ethics}

The study protocol was approved in 2005 by the Regional Committee for Medical Research Ethics in Eastern Norway, the National Data Inspectorate and the Norwegian Social Science Data Services. All subjects provided written consent before participating.

\section{Statistical analyses}

Differences between participants and nonparticipants included in the screening sample were analyzed by Student's $t$ test and Chi-square test for normally distributed continuous variables and categorical variables, respectively. The choice of categorization of measures of OSA severity in tertiles was based on the distribution of the AHI with the upper tertile close to the clinical cut-off between mild (AHI 5-14.9) and moderate (AHI 15-29.9) OSA [34]. Differences in cognitive scores between clinical cut-off values of the AHI and these tertiles in other measures of OSA severity were analyzed by one-way ANOVA with Bonferroni post hoc test. Two-sided $P$ values $<0.05$ were considered statistically significant. Comparisons of cognitive test results between groups of putative confounders were performed with Student's $t$ test. Standard multiple regression models adjusting for age, gender and higher education were used to examine the effect of OSA severity on test results. Because of missing information regarding polysomnography data $(n=1)$, oxygen saturation data $(n=2)$, higher education $(n=5)$, RAVLT $(n=4)$, and Stroop test $(n=2)$, the numbers of participants included in multivariate analyses declined to a minimum of 281 . Nonnormal variables assessing OSA severity were logarithmically transformed. Standard models were finally adjusted by adding putative confounders and strata variables one by one to these basic models. If a $15 \%$ change in the coefficient of the measure of OSA severity was observed, the variable was included in the final model. Interaction analyses and analyses of alternative distributions of measures of OSA severity were performed. All statistical analyses were obtained by using the Statistical Package for Social Sciences, version 16.0.

\section{Results}

Sociodemographic and clinical characteristics are displayed in Table 1. There were no significant differences in age, gender, snoring, obesity, or history of hypertension between the 290 participants and the 3,670 nonparticipants. However, a 
significantly higher proportion of participants than nonparticipants were classified in the daytime somnolence category (participants $70.7 \%$, nonparticipants $62.5 \%$ ), and in the EDS category (participants 43.1\%, nonparticipants $33.0 \%$ ). Five persons fulfilled the diagnostic criteria for alcohol abuse/dependency.

The mean RAVLT score and Stroop interference time among all participants were 42.0 words retrieved $(\mathrm{SD}=8.9)$ and $31.1 \mathrm{~s}(\mathrm{SD}=12.7)$, respectively. Compared with available norms $[35,36]$, the group performed 1.3 to 1.2 standard deviations below normal mean. Unadjusted mean cognitive test scores by commonly used cut-points for the AHI and tertiles of nadir- and average oxygen saturation are displayed in Table 2. Participants with AHI $\geq 15$ had significantly longer mean interference times on the Stroop test than participants without OSA $(p=0.001)$. A similar pattern with a significant loss of cognitive performance among participants in the tertile with the most severe versus mildest oxygen saturation was seen when categorized by lowest mean nadir oxygen saturation (83.0-54.0) and mean average oxygen saturation (93.8-81.8). Similar but less discriminant patterns were seen for tertiles of the $4 \%$ ODI and percent time $<90 \%$ saturation (data not shown). Cognitive test scores did not differ significantly between tertiles of the arousal index (data not shown).

Bivariate differences in cognitive scores by putative confounders are displayed in Table 3 . Correlation coefficients between the Stroop interference times and standard blood samples were not significant. Correlation coefficients between the RAVLT score and blood hemoglobin and serum ferritin were $-0.168(p=0.005)$ and $-0.120(p=0.046)$, respectively. The ESS was not significantly related to any of the cognitive tests (data not shown).

The final multiple regression models for the RAVLT score and Stroop interference time with average oxygen saturation as the independent variable assessing OSA severity are presented in Tables 4 and 5. Average oxygen saturation was found to be independently related to the RAVLT score but not to the Stroop test.

Neither logarithmically transformed AHI, nadir oxygen saturation, nor 4\% ODI were independently related to the RAVLT score and the Stroop interference time (Online Resource, Tables 1-4). Percent time $<90 \%$ was not independently related to the RAVLT score but to the Stroop interference time when adjusted for age, gender, and higher education (Online Resource, Tables 7-8). However, this association disappeared when BMI or BQ risk categories were added to the model.

\section{Discussion}

To our knowledge, this is the first study to describe verbal memory and executive function in community-dwelling

Table 2 Unadjusted mean cognitive test scores by established cut-off values of the AHI or tertiles of nadir- and average oxygen saturation

\begin{tabular}{|c|c|c|c|c|c|}
\hline Test & $\begin{array}{l}\text { Category } 1 \\
n \text { (range) } \\
\text { Mean } \pm \text { SD }\end{array}$ & $\begin{array}{l}\text { Category } 2 \\
n \text { (range) } \\
\text { Mean } \pm \text { SD }\end{array}$ & $\begin{array}{l}\text { Category } 3 \\
n \text { (range) } \\
\text { Mean } \pm \text { SD }\end{array}$ & $\begin{array}{l}F \text { test }^{\mathrm{a}} \\
p \text { Value }\end{array}$ & $\begin{array}{l}\text { Trend test } \\
p \text { Value }\end{array}$ \\
\hline & AHI & AHI & AHI & & \\
\hline & $111(0.0-4.9)$ & $70(5.0-14.9)$ & $104(15.0-104.0)$ & & \\
\hline RAVLT score ${ }^{b}$ & $43.2 \pm 8.2$ & $41.8 \pm 9.4$ & $40.7 \pm 9.3$ & 0.109 & 0.036 \\
\hline \multirow[t]{3}{*}{ Stroop interference time ${ }^{c}$} & $28.4 \pm 12.0^{*}$ & $30.5 \pm 11.5$ & $34.5 \pm 13.6$ & 0.001 & $<0.001$ \\
\hline & Upper tertile nadir $\mathrm{O}_{2}$ & Mid tertile nadir $\mathrm{O}_{2}$ & Lower tertile nadir $\mathrm{O}_{2}$ & & \\
\hline & $85(95.0 \%-89.0 \%)$ & $110(88.0 \%-84.0 \%)$ & $93(83.0 \%-54.0 \%)$ & & \\
\hline RAVLT score ${ }^{b}$ & $43.2 \pm 8.4^{*}$ & $42.9 \pm 8.2 *$ & $39.7 \pm 9.9$ & 0.010 & 0.008 \\
\hline \multirow[t]{3}{*}{ Stroop interference time $e^{c}$} & $29.2 \pm 12.5^{*}$ & $29.1 \pm 11.8^{*}$ & $35.5 \pm 13.0$ & $<0.001$ & 0.001 \\
\hline & Upper tertile average $\mathrm{O}_{2}$ & Mid tertile average $\mathrm{O}_{2}$ & Low tertile average $\mathrm{O}_{2}$ & & \\
\hline & $97(97.8 \%-95.3 \%)$ & $93(95.2 \%-93.9 \%)$ & $98(93.8 \%-81.8 \%)$ & & \\
\hline RAVLT score ${ }^{b}$ & $45.5 \pm 8.9 *$ & $41.6 \pm 8.4$ & $38.8 \pm 9.5)$ & $<0.001$ & $<0.001$ \\
\hline Stroop interference time $e^{\mathrm{c}}$ & $27.2 \pm 9.7 *$ & $32.7 \pm 14.4$ & $33.7 \pm 12.8)$ & $<0.001$ & $<0.001$ \\
\hline
\end{tabular}

a Test for overall model fit

${ }^{\mathrm{b}}$ Sum of trials $1-5$

${ }^{\mathrm{c}}$ Difference in seconds

${ }^{*} p<0.05$ for post hoc tests between category 1 and the two other categories identified by Bonferroni post hoc tests $A H I$ apnea-hypopnea index, RAVLT Rey Auditory Verbal Learning Test 
Table 3 RAVLT score and Stroop interference time according to cofactors
${ }^{a}$ Rey Auditory Verbal Learning Test, sum of trials $1-5$

${ }^{\mathrm{b}}$ Difference in seconds

$M I$ myocardial infarction

\begin{tabular}{|c|c|c|c|c|c|c|}
\hline & Number & $\begin{array}{l}\text { RAVLT } \\
\text { score }^{\mathrm{a}} \\
\text { Mean } \pm \text { SD }\end{array}$ & $p$ Value & Number & $\begin{array}{l}\text { STROOP interference time } \\
\text { Mean } \pm \text { SD }\end{array}$ & $p$ Value \\
\hline \multicolumn{7}{|l|}{ Gender } \\
\hline $\begin{array}{l}\text { Male } \\
\text { Female }\end{array}$ & $\begin{array}{l}161 \\
125\end{array}$ & $\begin{array}{l}39.8 \pm 9.1 \\
44.6 \pm 8.0\end{array}$ & $<0.001$ & $\begin{array}{l}160 \\
128\end{array}$ & $\begin{array}{l}31.8 \pm 13.6 \\
30.5 \pm 11.7\end{array}$ & 0.365 \\
\hline \multicolumn{7}{|c|}{ Higher education } \\
\hline $\begin{array}{l}\text { Yes } \\
\text { No }\end{array}$ & $\begin{array}{l}79 \\
203\end{array}$ & $\begin{array}{l}45.8 \pm 8.1 \\
40.6 \pm 8.8\end{array}$ & $<0.001$ & $\begin{array}{l}80 \\
203\end{array}$ & $\begin{array}{l}28.9 \pm 11.4 \\
31.7 \pm 13.0\end{array}$ & 0.088 \\
\hline \multicolumn{7}{|l|}{ Smoking } \\
\hline $\begin{array}{l}\text { Yes } \\
\text { No }\end{array}$ & $\begin{array}{l}88 \\
195\end{array}$ & $\begin{array}{l}41.8 \pm 8.7 \\
42.0 \pm 9.1\end{array}$ & 0.876 & 89 & $\begin{array}{l}30.2 \pm 12.3 \\
31.8 \pm 13.1\end{array}$ & 0.327 \\
\hline \multicolumn{7}{|c|}{ Self-reported asthma } \\
\hline $\begin{array}{l}\text { Yes } \\
\text { No }\end{array}$ & $\begin{array}{l}48 \\
214\end{array}$ & $\begin{array}{l}42.1 \pm 9.9 \\
42.2 \pm 8.7\end{array}$ & 0.905 & $\begin{array}{l}49 \\
216\end{array}$ & $\begin{array}{l}33.7 \pm 14.9 \\
30.6 \pm 12.5\end{array}$ & 0.134 \\
\hline \multicolumn{7}{|c|}{ Use of hypnosedatives } \\
\hline $\begin{array}{l}\text { Yes } \\
\text { No }\end{array}$ & $\begin{array}{l}15 \\
271\end{array}$ & $\begin{array}{l}42.1 \pm 8.9 \\
38.4 \pm 8.9\end{array}$ & 0.117 & $\begin{array}{l}15 \\
273\end{array}$ & $\begin{array}{l}38.4 \pm 18.2 \\
30.8 \pm 12.4\end{array}$ & 0.132 \\
\hline
\end{tabular}

adults at high risk of having OSA, as identified by the BQ. Verbal memory was found to be independently related to average oxygen saturation, while executive function was not related to OSA severity. The AHI, which is the most commonly used measure when assessing OSA severity, was only related to cognitive function in bivariate analyses. The arousal index was not related to cognitive function in any analysis.

The recruitment of participants by the BQ in this study resulted in a sample of participants with a relatively low median AHI of 7.7 (25th percentile $=2.4$, 75th percentile $=22.2$ ) compared with clinical studies of OSA. However, more than

Table 4 Final model for RAVLT score fitted by age, gender, education, average oxygen saturation, and covariates

\begin{tabular}{lrrr}
\hline$n=281$ (adjusted $\left.R^{2}=0.199 ; p<0.001\right)^{\mathrm{a}}$ & $\beta^{\mathrm{b}}$ & \multicolumn{1}{c}{$\mathrm{SE}^{\mathrm{c}}$} & $p$ Value \\
\hline Intercept & -19.278 & 32.969 & 0.559 \\
Gender $(0=$ female, $1=$ male) & -3.251 & 1.033 & 0.002 \\
Age $^{\mathrm{d}}$ & -0.168 & 0.047 & $<0.001$ \\
Higher education $^{\mathrm{e}}$ & 4.722 & 1.076 & $<0.001$ \\
Average oxygen saturation $_{\text {Body mass index }}$ & 0.721 & 0.320 & 0.025 \\
\hline
\end{tabular}

${ }^{a}$ Results from multiple regression analysis. Inclusion of the variables smoking, self-reported myocardial infarction, sleepiness, use of antidepressants, and use of hypnosedatives in the model did not affect the relationship between any covariate on the dependent variables

${ }^{\mathrm{b}} \beta$ is the unstandardized regression coefficient of the variable

${ }^{\mathrm{c}} \mathrm{SE}$ is the standard error of $\beta$

${ }^{\mathrm{d}}$ Unit of age, 5 years

${ }^{\mathrm{e}}$ College or university one third of the sample had an AHI of $\geq 15$, which is the criteria for moderate to severe OSA [34]. The cognitive function scores among participants were considerably higher than that reported in "mild cognitive impairment", which is the mildest clinical entity of impaired cognitive function [37]. However, the mean age of participants in this study was considerably lower than the mean age of patients with mild cognitive impairment [37]. Thus, our study adds knowledge to epidemiological factors associated with early cognitive decline rather than being a study of cognitively impaired subjects per se.

Studies in the last 5 years have confirmed that verbal memory is particularly affected by OSA pathology [7, 8]. On the other hand, the association between OSA and the complex executive function may be spurious $[8,11,17]$ and potentially influenced by attention [5, 38]. Unfortunately, no objective measures of attention were available in the ASAP. Accordingly, the Stroop interference time test, which provides adjustment for baseline speed [5], was chosen.

We have not identified any previous studies that have reported test results from the RAVLT or the Comali/ Kaplan Stroop test in community-based OSA populations. We therefore compared the RAVLT score with general population norms [35] and the Stroop interference time with an available clinical sample [36]. Both results indicate mildly impaired cognitive function. RAVLT scores are equivalent with general population norms of persons 20-30 years older than the actual age of participants of the study [35].

The salient finding of the second aim of this study was the support of our hypothesis that oxygen saturation, rather than the AHI or the arousal index, was associated with 
Table 5 Model for Stroop interference time fitted by age, gender, education, average oxygen saturation and covariates

\begin{tabular}{lrrr}
\hline$n=282\left(\text { adjusted } R^{2}=0.223, p<0.001\right)^{\mathrm{a}}$ & \multicolumn{1}{l}{$\beta^{\mathrm{b}}$} & \multicolumn{1}{l}{$\mathrm{SE}^{\mathrm{c}}$} & $p$ Value \\
\hline Intercept & 35.389 & 48.319 & 0.465 \\
Gender $(0=$ female, $1=$ male) & 0.105 & 1.507 & 0.944 \\
Age $^{\mathrm{d}}$ & 0.494 & 0.068 & $<0.001$ \\
Higher education $^{\mathrm{e}}$ & -3.047 & 1.551 & 0.051 \\
Average oxygen saturation & -0.360 & 0.470 & 0.444 \\
Body mass index & 0.206 & 0.156 & 0.189 \\
Self-reported asthma & 2.331 & 1.857 & 0.211 \\
\hline
\end{tabular}

${ }^{a}$ Results from multiple regression analysis. Inclusion of the variables smoking, logAHI, myocardial infarction, sleepiness, use of antidepressants, and use of hypnosedatives in the model did not affect the relationship between any covariate on the dependent variables

${ }^{\mathrm{b}} \beta$ is the unstandardized regression coefficient of the variable

${ }^{\mathrm{c}} \mathrm{SE}$ is the standard error of $\beta$

${ }^{\mathrm{d}}$ Unit of age, 5 years

${ }^{\mathrm{e}}$ College or university

verbal learning and executive function after adjusting for age, gender, higher education, and putative confounders. Smoking, alcohol consumption, and subjective sleepiness were not related to cognitive test scores and thus were not putative confounders of the associations examined.

Regarding the AHI, the fact that cognitive test scores differed significantly by tertiles of the AHI only in bivariate analyses (Table 2) suggests that the association between AHI and cognitive function was potentially mediated by covariates included in the final multiple regression analysis. On the other hand, this is unlikely because the association between the AHI and both cognitive test scores disappeared when age, gender, and higher education, which are unlikely mediators of this association, were adjusted for. Regarding potential effect modification between the AHI and these covariates, no interaction terms were significant when added, one pair at a time, to the multivariate models of AHI and verbal memory and executive function, respectively.

Regarding oxygen saturation, a novel finding in our study was that average oxygen saturation, rather than the commonly used variables, explained most of the variation in cognitive function. The effect of average oxygen saturation has, somewhat surprisingly, not been reported in any of the eight identified previous community-based studies or studies of mild OSA [12-17]. Studies of cognitive function in clinical samples of moderate to severe OSA have reported a similar level of average oxygen saturation as our study [7, $39,40]$, and a recent study also found that average oxygen saturation was an independent predictor of cognitive decline in middle-aged adults with moderate to severe OSA [41]. This finding was age-dependent.
We believe that the lack of an association between the arousal index and measures of cognitive function should be understood in relation to our finding of an independent association with oxygen saturation. Objective sleep quality has traditionally been more strongly associated with memory consolidation than hypoxia [42]. However, regarding OSA, accumulating evidence from studies applying neuroimaging techniques [43-45] and studies of animal models [46, 47] indicates that intermittent hypoxia is the most important cause of neural injury related to this disorder over time.

Finally, it should be kept in mind that different variables assessing intermittent hypoxia or oxygen saturation might be related to other aspects of chronic disease than OSA, such as the nonlinear oxygen dissociation curve, abdominal obesity limiting the functional residual capacity, or other lung diseases. It is therefore interesting that the relations between average oxygen saturation and cognitive function were not altered by the inclusion of blood hemoglobin and serum ferritin in the multivariate models. Regarding obesity, BMI only slightly altered the association between average oxygen saturation and the cognitive test results. The multiple regression model for Stroop interference time was adjusted for potential confounding by self-reported asthma. Asthma was not found to be related to the association between average oxygen saturation and the RAVLT score.

In summary, the finding of an independent association between oxygen saturation, rather than the AHI or the arousal index, with early cognitive decline in participants with high risk of OSA emphasizes that future studies should specify variables of OSA severity prior to analysis. Future studies should also include enough subjects to allow adjustment for putative confounders. Regarding which variables to assess, we argue that average oxygen saturation and other variables assessed through the whole night $(4 \%$ ODI, percentage time below $90 \%$ saturation) should be considered in community-based samples or studies of mild OSA because of the advantage of being less vulnerable to artifacts than, for example, the nadir oxygen saturation.

Strengths and limitations

The use of polysomnography to assess OSA severity in a large, community-based sample is an obvious strength. However, the use of only a single, hospital-based polysomnography recording is a potential limitation of the study [48]. Therefore, the possible first night effect could not be controlled for. It remains unknown what, if any, effect it may have had on indicators of OSA severity.

Another strength of the study is that cognitive tests were performed by the same physician at identical time points the day prior to the polysomnography. Both tests were suggested by Decary et al. [2] for use in OSA patients, although the 
limited number of tests increased the probability of a type 2 statistical error (i.e., finding no association when the association is truly present). The cognitive tests should ideally have been performed after the sleep studies, but with the chronic nature of OSA, we consider this to be only a minor weakness.

Regarding potential limitations, the relatively low response, and participation rates biased the sample towards including participants with more daytime impairments. However, we believe that this mechanism did not significantly affect our findings because daytime impairments did not contribute to the multivariate models displayed in Tables 4 and 5 .

The multivariate models should ideally have been adjusted for diagnosed asthma rather than self-reported asthma and more putative confounders such as better measures of attention [9] or inflammation [49]. However, the statistical models in this study are adjusted for more putative confounders than most previous communitybased studies of the relation between OSA and cognitive function.

Finally, the cross-sectional design and the lack of a control group were limitations to causal interpretations. The crosssectional design also limited us from including variables in the multivariate models that assessed psychological distress because it could not be determined whether psychological distress would be a cause or a consequence of cognitive impairment.

\section{Conclusion}

Verbal memory and executive function were mildly impaired in community-dwelling adults at high risk of OSA. The data supported the hypothesis that memory decline in OSA, as measured by the RAVLT score, is more strongly related to oxygen desaturation than the AHI or the arousal index. Average oxygen saturation during sleep, rather than traditional variables assessing oxygen saturation related to OSA, was the variable that was most strongly related to the RAVLT score. No independent relations were found between executive function, as measured by the Stroop interference time, and variables of OSA severity. The effect of average oxygen saturation on cognitive function should be explored in future studies.

Acknowledgments We would like to thank Akershus University Hospital for providing research facilities and the Institute for Clinical Medicine, Akershus University Hospital, for providing technical support (Anita Fjellum and Gunn Seim Eikeland). Finally, we acknowledge the staff at, Department Stensby Hospital, for their flexibility and friendly support while collecting data for this study.

Conflicts of interest All authors except Torbjørn Omland declare that they have no conflict of interest. Torbjørn Omland has received speaker honoraria from Roche and Abbott (<10.000 USD).
Open Access This article is distributed under the terms of the Creative Commons Attribution Noncommercial License which permits any noncommercial use, distribution, and reproduction in any medium, provided the original author(s) and source are credited.

\section{References}

1. Engleman H, Joffe D (1999) Neuropsychological function in obstructive sleep apnoea. Sleep Med Rev 3:59-78

2. Decary A, Rouleau I, Montplaisir J (2000) Cognitive deficits associated with sleep apnea syndrome: a proposed neuropsychological test battery. Sleep 23:369-381

3. Beebe DW, Groesz L, Wells C, Nichols A, McGee K (2003) The neuropsychological effects of obstructive sleep apnea: a meta-analysis of norm-referenced and case-controlled data. Sleep 26:298-307

4. Aloia MS, Arnedt JT, Davis JD, Riggs RL, Byrd D (2004) Neuropsychological sequelae of obstructive sleep apnea-hypopnea syndrome: a critical review. J Int Neuropsychol Soc 10:772-785

5. Verstraeten E, Cluydts R (2004) Executive control of attention in sleep apnea patients: theoretical concepts and methodological considerations. Sleep Med Rev 8:257-267

6. Saunamaki T, Jehkonen M (2007) A review of executive functions in obstructive sleep apnea syndrome. Acta Neurol Scand 115(1):1-11

7. Naegele B, Launois SH, Mazza S, Feuerstein C, Pepin JL, Levy P (2006) Which memory processes are affected in patients with obstructive sleep apnea? An evaluation of 3 types of memory. Sleep 29:533-544

8. Twigg GL, Papaioannou I, Jackson M, Ghiassi R, Shaikh Z, Jaye J, Graham KS, Simonds AK, Morrell MJ (2010) Obstructive sleep apnoea syndrome is associated with deficits in verbal but not visual memory. Am J Respir Crit Care Med 182:98-103

9. Verstraeten E, Cluydts R, Pevernagie D, Hoffmann G (2004) Executive function in sleep apnea: controlling for attentional capacity in assessing executive attention. Sleep 27:685-693

10. Lis S, Krieger S, Hennig D, Roder C, Kirsch P, Seeger W, Gallhofer B, Schulz R (2008) Executive functions and cognitive subprocesses in patients with obstructive sleep apnoea. J Sleep Res 17:271-280

11. Saunamaki T, Himanen SL, Polo O, Jehkonen M (2009) Executive dysfunction in patients with obstructive sleep apnea syndrome. Eur Neurol 62:237-242

12. Berry DT, Phillips BA, Cook YR, Schmitt FA, Gilmore RL, Patel R, Keener TM, Tyre E (1987) Sleep-disordered breathing in healthy aged persons: possible daytime sequelae. J Gerontol 42:620-626

13. Telakivi T, Kajaste S, Partinen M, Koskenvuo M, Salmi T, Kaprio J (1988) Cognitive function in middle-aged snorers and controls: role of excessive daytime somnolence and sleep-related hypoxic events. Sleep 11:454-462

14. Hayward L, Mant A, Eyland A, Hewitt H, Purcell C, Turner J, Goode E, Le CA, Pond D, Saunders N (1992) Sleep disordered breathing and cognitive function in a retirement village population. Age Ageing 21:121-128

15. Kim HC, Young T, Matthews CG, Weber SM, Woodward AR, Palta M (1997) Sleep-disordered breathing and neuropsychological deficits. A population-based study. Am J Respir Crit Care Med 156:1813-1819

16. Boland LL, Shahar E, Iber C, Knopman DS, Kuo TF, Nieto FJ (2002) Measures of cognitive function in persons with varying degrees of sleep-disordered breathing: the Sleep Heart Health Study. J Sleep Res 11:265-272

17. Quan SF, Wright R, Baldwin CM, Kaemingk KL, Goodwin JL, Kuo TF, Kaszniak A, Boland LL, Caccappolo E, Bootzin RR (2006) Obstructive sleep apnea-hypopnea and neurocognitive functioning in the Sleep Heart Health Study. Sleep Med 7:498-507 
18. Sforza E, Roche F, Thomas-Anterion C, Kerleroux J, Beauchet O, Celle S, Maudoux D, Pichot V, Laurent B, Barthelemy JC (2010) Cognitive function and sleep related breathing disorders in a healthy elderly population: the SYNAPSE study. Sleep 33:515521

19. Redline S, Strauss ME, Adams N, Winters M, Roebuck T, Spry K, Rosenberg C, Adams K (1997) Neuropsychological function in mild sleep-disordered breathing. Sleep 20:160-167

20. Adams N, Strauss M, Schluchter M, Redline S (2001) Relation of measures of sleep-disordered breathing to neuropsychological functioning. Am J Respir Crit Care Med 163:1626-1631

21. Morgan BJ, Reichmuth KJ, Peppard PE, Finn L, Barczi SR, Young T, Nieto FJ (2010) Effects of sleep disordered breathing on cerebrovascular regulation: a population-based study. Am J Respir Crit Care Med 182:1445-1452

22. Netzer NC, Stoohs RA, Netzer CM, Clark K, Strohl KP (1999) Using the Berlin Questionnaire to identify patients at risk for the sleep apnea syndrome. Ann Intern Med 131:485-491

23. Hiestand DM, Britz P, Goldman M, Phillips B (2006) Prevalence of symptoms and risk of sleep apnea in the US population: results from the national sleep foundation sleep in America 2005 poll. Chest 130:780-786

24. Kapsimalis F, Kryger M (2009) Sleep breathing disorders in the U.S. female population. J Womens Health 18:1211-1219

25. Hrubos-Strom H, Randby A, Namtvedt SK, Kristiansen HA, Einvik G, Benth J, Somers VK, Nordhus IH, Russell MB, Dammen T, Omland T, Kvaerner KJ (2010) A Norwegian population-based study on the risk and prevalence of obstructive sleep apnea. J Sleep Res [Epub ahead of print]

26. Chung F, Yegneswaran B, Liao P, Chung SA, Vairavanathan S, Islam S, Khajehdehi A, Shapiro CM (2008) Validation of the Berlin questionnaire and American Society of Anesthesiologists checklist as screening tools for obstructive sleep apnea in surgical patients. Anesthesiology 108:822-830

27. Schmidt M (1996) Rey auditory and verbal learning test. A handbook. Western Psychological Services, Los Angeles

28. Egeland J, Rund BR, Sundet K, Landro NI, Asbjornsen A, Lund A, Roness A, Stordal KI, Hugdahl K (2003) Attention profile in schizophrenia compared with depression: differential effects of processing speed, selective attention and vigilance. Acta Psychiatr Scand 108:276-284

29. Rechtshaffen A, Kales A (1968) A manual of standardized terminology and scoring system for sleep stages of human sleep. University of California at Los Angeles, Brain Information Service/Brain Research Institute, Los Angeles

30. American Sleep Disorders Association (1992) EEG arousal: scoring rules and examples. Sleep 15:174-184

31. First Michael B, Spitzer Robert L, Gibbon Miriam, Williams Janet BW (1995) Structured Clinical Interview for DSM-IV Axis I Disorders, patient edition (SCID-I/P), version 2.0, Norwegian version

32. Beiske KK, Kjelsberg FN, Ruud EA, Stavem K (2009) Reliability and validity of a Norwegian version of the Epworth sleepiness scale. Sleep Breath 13:65-72
33. Johns MW (1991) A new method for measuring daytime sleepiness: the Epworth sleepiness scale. Sleep 14:540-545

34. American Academy of Sleep Medicine (2005) International classification of sleep disorders: diagnostic and coding manual. American Academy of Sleep Medicine, Westchester

35. Mitrushina M, Boone KB, Razani J, D'elia LF (2005) Handbook for normative data for neuropsychological assessment. Oxford Press, New York

36. Rund BR, Sundet K, Asbjornsen A, Egeland J, Landro NI, Lund A, Roness A, Stordal KI, Hugdahl K (2006) Neuropsychological test profiles in schizophrenia and non-psychotic depression. Acta Psychiatr Scand 113:350-359

37. Petersen RC, Smith GE, Waring SC, Ivnik RJ, Tangalos EG, Kokmen E (1999) Mild cognitive impairment: clinical characterization and outcome. Arch Neurol 56:303-308

38. Gosselin N, Mathieu A, Mazza S, Petit D, Malo J, Montplaisir J (2006) Attentional deficits in patients with obstructive sleep apnea syndrome: an event-related potential study. Clin Neurophysiol $117: 2235$

39. Alchanatis M, Zias N, Deligiorgis N, Amfilochiou A, Dionellis G, Orphanidou D (2005) Sleep apnea-related cognitive deficits and intelligence: an implication of cognitive reserve theory. J Sleep Res 14:69-75

40. Mathieu A, Mazza S, Decary A, Massicotte-Marquez J, Petit D, Gosselin N, Malo J, Montplaisir J (2008) Effects of obstructive sleep apnea on cognitive function: a comparison between younger and older OSAS patients. Sleep Med 9:112-120

41. Alchanatis M, Zias N, Deligiorgis N, Liappas I, Chroneou A, Soldatos C, Roussos C (2008) Comparison of cognitive performance among different age groups in patients with obstructive sleep apnea. Sleep Breath 12:17-24

42. Stickgold R (2005) Sleep-dependent memory consolidation. Nature 437:1272-1278

43. Zimmerman ME, Aloia MS (2006) A review of neuroimaging in obstructive sleep apnea. J Clin Sleep Med 2:461-471

44. Ayalon L, Peterson S (2007) Functional central nervous system imaging in the investigation of obstructive sleep apnea. Curr Opin Pulm Med 13:479-483

45. Yaouhi K, Bertran F, Clochon P, Mezenge F, Denise P, Foret J, Eustache F, Desgranges B (2009) A combined neuropsychological and brain imaging study of obstructive sleep apnea. J Sleep Res $18: 36-48$

46. Brzecka A (2005) Brain preconditioning and obstructive sleep apnea syndrome. Acta Neurobiol Exp 65:220

47. Veasey S (2009) Insight from animal models into the cognitive consequences of adult sleep-disordered breathing. ILAR J 50:307-311

48. Stepnowsky CJ Jr, Orr WC, Davidson TM (2004) Nightly variability of sleep-disordered breathing measured over 3 nights. Otolaryngol Head Neck Surg 131:837-843

49. Haensel A, Bardwell WA, Mills PJ, Loredo JS, Ancoli-Israel S, Morgan EE, Heaton RK, Dimsdale JE (2009) Relationship between inflammation and cognitive function in obstructive sleep apnea. Sleep Breath 13:35-41 